\title{
GAMBARAN PELAKSANAAN PROGRAM TRIAS UKS DAN SARANA PRASARANA UKS TERHADAP KUALITAS PELAYANAN UKS PADA TINGKAT SEKOLAH DASAR DI WILAYAH KERJA KECAMATAN TANAH SAREAL KOTA BOGOR TAHUN 2018
}

\author{
Zakia Arranur Syira ${ }^{1)}$, Asri Masitha Arsyati ${ }^{2)}$, Husnah Maryati ${ }^{3)}$ \\ ${ }^{1)}$ Konsentrasi Manajemen Pelayanan Kesehatan, Program Studi Kesehatan Masyarakat, Fakultas Ilmu Kesehatan \\ Universitas Ibn Khaldun Bogor \\ Email: zaqiasyira@gmail.com \\ ${ }^{2)}$ Program Studi Kesehatan Masyarakat, Fakultas Ilmu Kesehatan Universitas Ibn Khaldun Bogor \\ Email: asri.masitha@gmail.com \\ ${ }^{3)}$ Program Studi Kesehatan Masyarakat, Fakultas Ilmu Kesehatan Universitas Ibn Khaldun Bogor \\ Email: anatanzili@gmail.com
}

\begin{abstract}
Abstrak
Menurut laporan Sistem Informasi Rumah Sakit (SIRS) tahun 2014, sebagian besar kematian yang terjadi pada anak usia sekolah mengacu pada kematian karena kurangnya PHBS di sekolah maupun rumah. Tujuan dari penelitian ini adalah memperoleh informasi secara mendalam tentang faktorfaktor yang berhubungan dengan kualitas pelayanan usaha kesehatan sekolah pada tingkat sekolah dasar se-Kecamatan Tanah Sareal Kota Bogor tahun 2018. Rancangan pada penelitian ini menggunakan penelitian kualitatif. Populasi dalam penelitian ini adalah seluruh sekolah yang ada di Kecamatan Tanah Sareal yang berjumlah 41 sekolah dengan teknik purposive sampling. Alat yang digunakan dalam penelitian ini yaitu daftar tilik observasi dan pedoman wawancara dengan cara analisa data menggunakan prosedur cek ulang (rechecking) secara cermat. Hasil penelitian didapatkan faktor-faktor apa saja yang mempengaruhi kualitas pelayanan UKS pada tingkat sekolah dasar yaitu pengetahuan yang dimiliki kepala sekolah dan guru masih kurang mengenai kegiatan pokok UKS, sikap kepala sekolah dan guru masih belum terlalu mementingkan kualitas UKS namun hanya memberikan seadanya. Kurangnya sarana prasarana yang disubsidikan dari pemerintah masih terlalu minimal sehingga masih banyak sarana prasarana yang dirasa kurang. Umur sasaran utama UKS pada umumya seluruh kelas tidak ada klasifikasi umur dalam sasaran utama UKS, serta kurangnya dukungan dari pihak pemerintah, petugas kesehatan serta warga sekolah mengenai kualitas UKS. Kesimpulan dari penelitian ini adalah pengetahuan, sikap, sarana prasarana, umur, dan dukungan dari pihak terkait sangat berpengaruh terhadap kualitas pelayanan UKS terutama sarana prasarana. Saran yang dapat diberikan untuk sekolah di Kecamatan Tanah Sareal dapat dijadikan masukan dalam rangka menyusun perencanaan program UKS yang lebih baik lagi.
\end{abstract}

\section{PENDAHULUAN}

Anak usia sekolah merupakan generasi muda aset penerus bangsa pada masa yang akan datang. Bangsa yang sehat, berkualitas,

produktif, dan berdaya saing sangat ditentukan oleh derajat kesehatan dan kualitas hidup pada kelompok umur ini 
(Departemen Kesehatan, 2015).

World health organitation (WHO) melaporkan bahwa 5-25\% anak-anak usia sekolah menderita disfungsi otak minor,termasuk gangguan perkembangan motorik halus (Widati,2012). Sedangkan menurut (Kay-Lambkin, dkk, 2007) secara global dilaporkan anak yang mengalami gangguan berupa kecemasan sekitar 9\%, mudah emosi $11-15 \%$, gangguan perilaku 915\%. Departemen kesehatan RI Dalam (Widati, 2012) melaporkan bahwa 0,4 juta (16\%) balita Indonesia mengalami gangguan perkembangan, baik perkembangan motorik halus dan kasar, gangguan pendengaran, kecerdasan kurang dan keterlambatan bicara. Sedangkan menurut Dinas Kesehatan dalam (Widati, 2012) sebesar 85.779 (62,02\%) anak usia sekolah mengalami gangguan perkembangan.

Rumah sakit di Indonesia telah mengkelompokan 3 penyakit tertinggi yang sering terjadi pada anak sekolah dasar pada posisi pertama adalah diare terdapat 37.281 kasus yang diderita anak laki-laki dan 34.608 pada anak perempuan dan angka kematian yang diakibatkan oleh diare sebanyak 1.289 kematian. Selanjutnya penyakit tertinggi pada anak sekolah dasar yang kedua adalah Demam Berdarah Dengue (DBD) terjadi 30.232 kasus pada anak laki-laki dan 28.883 pada anak perempuan tercatat ada 325 kematian karena DBD. Dan yang terakhir adalah peyakit demam tifoid dan paratifoid dilaporkan ada 19.706 kasus yang menimpa anak laki-laki dan 21.375 pada anak perempuan dan terdapat sebanyak 274 kematian karena demam tifoid dan paratifoid. (Sistem Informasi Rumah Sakit, 2014)

Melihat hal tersebut dapat disimpulkan bahwa pelaksanaan UKS secara optimal sangatlah berperan penting, karena dalam tiga pokok utama program UKS (Trias UKS) yaitu Pendidikan Kesehatan, Pelayanan
Kesehatan dan Pembinaan Lingkungan Sekolah Sehat.

Survei sarana prasarana UKS di sekolah dasar negeri se-Kecamatan Banguntapan, Bantul (dimana) memberikan hasil 0 sekolah $(0 \%)$ berkategori sangat baik, 9 sekolah $(29,03 \%)$ berkategori baik, 14 sekolah $(45,16 \%)$ berkategori sedang, 7 sekolah $(22,58 \%)$ berkategori kurang dan 1 sekolah $(3,22 \%)$ berkategori sangat kurang, sehingga dapat disimpulkan secara keseluruhan adalah berkategori sedang (Munaha, 2013).

Survei pelaksanaan UKS di SD seKecamatam Kretek Kabupaten Bantul, hasil penelitian menunjukan bahwa secara keseluruhan pelaksanaan UKS terdapat 0 sekolah (0\%) dalam kategori sangat tinggi, 4 sekolah $(25,00 \%)$ dalam kategori tinggi, 7 sekolah $(43,75 \%)$ dalam kategori cukup, 4 sekolah $(25,00 \%)$ dalam kategori rendah, 1 sekolah $(6,25 \%)$ dalam kategori sangat rendah (Untara, 2013). Selain itu, penelitian tingkat pengelolaan UKS di SD Negeri seKecamatan Kokap, Kabupaten Kulon Progo menunjukan bahwa terdapat $6,4 \%$ (2 SD) pengelolaan UKS yang berada pada kategori sangat baik, 67\% (8 SD) pengelolaan yang berada dalam kategori baik, 32,2\% (10 SD) pengelolaan UKS yang berada pada kategori cukup baik, 29\% (9 SD) pengelolaan UKS pada kategori kurang baik, dan $6,4 \%$ (2 SD) berada dalam pengelolaan pada kategori tidak baik (Hermawan, 2015).

Pada saat ini ada sebanyak 258 sekolah dasar negeri yang tersebar di kota bogor dengan jumlah murid mencapai 84.620 murid. Dari 258 sekolah ada 202 sekolah yang memiliki UKS di sekolahnya masingmasing dan sisanya tidak memiliki atau belum memilki UKS. (Dinas Kesehatan, 2017)

Selain itu, Devita (2011) melakukan penelitian di wilayah puskesmas Pegandan- 
Semarang, yang mana berdasarkan hasil penelitian tersebut diharapkan adanya peningkatan pengetahuan guru UKS melalui pendampingan dan pelatihan oleh petugas puskesmas atau dinas kesehatan, perlunya peningkatan kesadaran diri oleh guru UKS maupun warga sekolah lainnya agar pelaksanaan UKS di sekolah lebih maksimal, perlunya perbaikan sarana dan prasarana untuk menunjang pelaksanaan kegiatan UKS di sekolah serta perlunya kerjasama antara pihak terkait lebih ditingkatkan agar

\section{METODE}

Penelitian ini merupakan penelitian studi kualitatif yang akan menggambarkan factor-faktor yang mempengaruhi kualitas pelayanan program usaha kesehatan sekolah (UKS) pada tingkat sekolah dasar di Kecamatan Tanah Sareal Kota Bogor. Desain penelitian ini menggunakan adalah Rappid Assessment Procedures (RAP).

Sampel dalam penelitian ini menggunakan teknik Purposive Sampling.Purposive Sampling adalah salah satu teknik sampling non random sampling dimana peneliti menentukan pengambilan sampel dengan cara menetapkan ciri-ciri khusus yang sesuai dengan tujuan penelitian sehingga diharapkan dapat menjawab permasalahan penelitian. Sampel dalam penelitian ini peneliti melakukan observasi ke pada 24 sekolah dasar yang ada di kecamatan tanah sareal dengan mempertimbangkan kriteria kelompok sampel 1 dan 2.

\section{Hasil Observasi}

Trias UKS adalah tiga tugas pokok yang wajib dijalankan disetiap sekolah yang memilki UKS sesuai dengan pedoman yang telah ditentukan. Didalam Trias UKS itu sendiri terdapat tiga kegiatan yaitu pendidikan kesehatan, pelayanan kesehatan dan pelaksanaan UKS di sekolah lebih maksimal (Devita, 2011).

Berdasarkan deskripsi diatas peneliti tertarik untuk melihat bagaimana gambaran mengenai pelaksanaan Trias UKS dan kelengkapan sarana praasarana UKS pada sekolah dasar di wilayah Kecamatan Tanah Sareal Kota Bogor. Pada penelitian ini akan menggunakan metode untuk mendapatkan Informasi secara cepat yaitu Rappid Assasement Procedures (RAP)

pembinaan lingkungan sekolah sehat. Peneliti telah melakukan observasi mengenai pelaksanaan Trias UKS di sekolah dasar dan peneliti menemukan hasil seperti berikut ini :

\section{Pelaksanaan Pendidikan Kesehatan dalam Trias UKS.}

Dalam pelaksanaan pendidikan peneliti menemukan bahwa seluruh sekolah hampir semua mendapatkan penyuluhan rutin hanya dari petugas kesehatan yang berasal dari Puskesmas saja sedangkan untuk penyuluhan dari kelompok profesi hanya 1 sekolah yang pernah mendapatkannya itupun hanya sekali.

\section{Pelaksanaan Pelayanan Kesehatan dalam Trias UKS.}

Dalam pelayanan kesehatan terdapat 4 poin yang harus dijalankan atau dilaksanakan oleh sekolah yang memiliki UKS yakni kegiatan promotif, preventif, kuratif dan rehabilitatif. Peneliti hanya memasukan 2 poin saja yaitu kuratif dan rehabilitatif dikarenakan untuk promotif dan preventif sudah termasuk kedalam poin pendidikan kesehatan. Hampir seluruh sekolah telah melakukan kegiatan kuratif (pengobatan) dalam bentuk memberikan pertolongan pertama terhadap murid. Sedangkan untuk rehabilitatif (Penyembuhan) sudah banyak 
yang melaksanaan kegiatan ini dalam bentuk menempatkan anak murid dengan gangguan mata minus selalu duduk dibarisan pertama.

\section{Pelaksanaan Pembinaan Lingkungan Sekolah Sehat dalam Trias UKS}

Pembinaan lingkungan sekolah sehat ini mencakup dua hal yaitu lingkungan fisik dan lingkungan mental. Peneliti melakukan observasi mengenai pembinaan lingkungan sehat menunjukan hasil bahwa seluruh sekolah hampir semua melaksanakan pembinaan lingkungan sekolah sehat termasuk pemeliharaan lingkungan fisik maupun mental.

\section{HASIL PENELITIAN}

\section{Karakteristik Informan}

Pada penelitian ini, penulis melakukan wawancara mendalam dengan 10 orang informan yang mewakili kompetensi masing-

\begin{tabular}{lllll}
\hline Kode Informan & Jenis & Umur & Pendidikan & Jabatan \\
& Kelamin & & & \\
\hline Informan 1a & Perempuan & 53 Tahun & S1 & Kepala Sekolah dan Guru \\
Informan 2a & Perempuan & 51 Tahun & S2 & Kepala Sekolah \\
Informan 3a & Perempuan & 52 Tahun & S1 PLS & Guru Olahraga \\
Informan 4a & Perempuan & 51 Tahun & S1 PLS & Guru Olahraga \\
Informan 1b & Laki-laki & 49 Tahun & S1 & Kepala Sekolah \\
Informan 2b & Perempuan & 52 Tahun & S1 & Kepala Sekolah \\
Informan 3b & Perempuan & 49 Tahun & S1 Pendidikan & Guru Olahraga \\
Informan 4b & Perempuan & 52 Tahun & S1 PLS & Guru Olahraga \\
Informan Kunci a & Perempuan & 52 Tahun & D3 Keperawatan & PJ program UKS \\
Informan Kunci b & Perempuan & 47 Tahun & D3 Keperawatan & PJ program UKS \\
\hline
\end{tabular}

\section{Pengetahuan}

Informasi yang ditanyakan mengenai pengetahuan dari UKS, tujuan UKS, pelatihan/pembinaan guru UKS, pencapaian program UKS, peranan UKS, TRIAS UKS, pendidikan kesehatan, pelayanan kesehatan, pembinaan lingkungan hidup sehat, lingkungan fisik dan lingkungan mental.

Pengetahuan tentang UKS sebagian besar sudah mengerti secara garis besar arti

\section{Sarana Prasarana UKS}

Sarana Prasarana UKS terdapat 3 kategori yang harus dimiliki oleh UKS di sekolah dengan 3 kategori tersebut sekolah dapat mengetahui bahwa peralatan apa saja yang mendukung untuk keberlangsungan dari UKS. 3 kategori tersebut adalah sarana prasarana sederhana, lengkap, dan ideal. Hampir seluruh sekolah yang diobservasi memiliki UKS yang berkategori lengkap. Namun ada beberapa sekolah yang memiliki kategori sederhana dan ideal.

masing serta dianggap representative terhadap obyek masalah dalam penelitian. Berikut tabel yang menunjukkan karakteristik informan : 
berikut:

“... eee tentang UKS disekolah yaitu untuk men.. apa kesehatan disekolah yah anak-anaknya kebersihan disekolah dan juga udah dibentuk dokcil yah" (Informan 3b)

"Ya.. UKS yang ada disekolah itu adalah eee usaha yah usaha sekolahyang dilakukan sekolah untuk meningkatkan kesehatan siswa/siswinya kesehatan disini bukan berarti untuk kaya dokter yah tapi kesahatan sehari-hari misalnya eee penimbangan berat badan, tinggi badan, pemeriksaan kuku, gigi yah pokonya panca indra dan kemudian pengawasan dalam eee makanan yah" (Informan 1a)

Hampir semua informan yang menjawab mengenai tujuan UKS adalah untuk meningkatkan derajat kesehatan anakanak, memberi pendidikan kesehatan kepada anak murid, memberikan pengetahuan kesehatan pribadi, menjaga kesehatan.Sedangkan ada informan yang menjawab tujuan dari UKS adalah untuk membersihkan. Seperi ungkapan berikut :

"Jelas tujuannya salah satunya dalah untuk me..ningkatkan kesehatan siswa yang... eee... untuk integen yah daya piker anak kemudian untuk mencegah penyakit yah yang timbul dari makanan maupun dari kebersihan di anak itu sendiri gitu”(Informan 1a)

“... untuk meningkatkan derajat kesehatan siswa disekolah” (Informan Kunci b)

“... tujuan dari uks adalah untuk apa membersihkan yah ini terus eeee.. menjaga kesehatan anak-anak dan untuk ee apa kalau anak-anak ada yang cedera diusahakan diuks" (Informan 3b)

Mengenai pencapaian program UKS di sekolah dasar kecamatan Tanah Sareal Bogor hampir semua menjawab pencapaiannya sudah baik dan berjalan da nada yang mengungkapkan bahwa pencapaian program UKS telah mencapai 98\%. Berikut adalah ungkapannya :

"Alhamdulillah sih kalau untuk kesehatan atau pemeriksaan pribadi siswa dilakukan setiap minggu yah seperti pemeriksaan gigi dan sebagainya kemudian ada juga kegiatan penyuluhan dari puskesmas gitu” (Informan 1a)

"Baik, sudah baik lumayan lah sudah ada dokcil juga" (Informan 2b)

“... saya cakupan saya baru 98\% kalau penjaringan harus $100 \%$ jadi saya masih kurang $\quad 2 \% \quad$ eh sorry $0,2 \%$ maksudnya"(Informan Kunci b)

Hampir dari semua informan menyatakan bahwa TRIAS UKS adalah segitiga hijau, program yang telah terlaksana atau terealisasikan.Sedangkan ada juga informan yang menjawab dengan benar seperti pendidikan kesehatan, lingkungan sehat dan pembinaan kesehatan. Berikut adalah ungkapannya :

"Trias UKS tiga yah tiga uks itu yah pak eman yah he.eh saya sebetulnya kurang terlalu mendetail yah silahkan Tanya kepada petugas UKSnya” (Informan 1a)

“... trias uks itu pendidikan kesehatan eeee.. lingkungan bersih dan sehat terus pembinaan kesehatan gitu aja"(Informa 1b)

Ketika ditanya mengenai program TRIAS UKS dalam bidang pendidikan kesehatan rata-rata informan menjawabnya masih dengan sepengetahuan yang informan punya seperti kebersihan makanan, kebersihan pribadi, jajan tidak boleh sembarngan. Namun ada pula yang telah mengerti apa itu pendidikan kesehatan seperi pendidikan mengenai penyuluhan kepada anak murid walaupun belum tepat tetapi setidaknya sudah mengerti. Seperti ungkapan berikut :

“... pendidikannya itu terintregrasi dalam $\mathrm{kbm}$ yah eeem terintegrasi nah didalam kbm itu kan ada misalnya bagaimana eee memelihara kesehatan tubuh dari mulai 
kegiatan anak dari pagi mandi dan sebagainya kemudian makanan sehat empat sempurna kemudian olahraga juga gitu dilakukan yah"(Informan 1a)

“... dalam pendidikan kesehatan yaa pendidikan aja misalnya tentang eee kebersihan mekanan kebersihan pribadi gitu aja" (Informan 1b)

"Eee kaya ngasih tau tentang kesehatan gitu aja teh” (Informan2b)

Hampir semua informan yang ditanyakan mengenai kegiatan pelayanan kesehatan dalam TRIAS UKS telah menjawab dengan benar yaitu sebagian menjawab kegiatan penjaringan kesehatan pada anak murid, dan memberikan pelayanan imunisasi kepada anak murid. Seperti ungkapan berikut ini :

"Eee... pelayanan teh kaya adanya penjaringan kesehatan di sekolah gitu untuk anak murid kelas 1 eemm da nada imunisasi imunisasi gitu yah" (Informan 1a)

“... eeh kegiatan ... imunisasi dari puskesmas seperti penyuntikkan pemeriksaan gigi, penjaringan” (Informan 3b)

\section{Sikap}

Informasi yang ditanyakan mengenai sikap terdiri dari pendapat mengenai kualitas UKS di sekolah dasar yang dipimpin, pendapat mengenai guru uks bertanggung jawab menjelaskan manfaat dari UKS kepada seluruh warga sekolah, dan bentuk keahlian apa saja yang harus dimiliki oleh seorang guru UKS.

Hampir semua informan yang ditanyakan mengenai kualitas uks semua menjawab sudah baik salah satuu informan menjawab dengan membawa nilai dari sarana prasarana yang sudah mumpuni. Seperti ungkapan berikut :

"Baik karna kita sudah memiliki sarana dan sudah berjalan” (Informan 1a)

“Baiklah yah lumayan” (Informan 2b)
“... pelayanan kita penjaringan kesehatan eeeee penata laksanaan anemia remaja dengan penanganan obesitas" (Informan Kunci a)

Hampir semua informan yang ditanyakan mengenai pembinaan lingkungan hidup sehat semuanya memberikan jawaban mengenai kebersihan lingkungan fisik, seperti melakukan buang sampah pada tempatnya melaksanakan Jum'at Bersih (Jumsih) jarang yang menjawab memebangun tali persaudaraan antar warga sekolah untuk memeiliharai lingkungan mental yang sehat. Berikut adalah ungkapanya :

“... pembinaan lingkungan ya dibiasakan untuk setiap inikan ada operasi semut misalnya ada sampah memungut sampah"'(Informan 1b)

“... iya sih kita selalu ada bersih-bersih setiap hari jumat" (Informan 2b)

"Lingkungan sehat ee itu apa membuang sampah tidak sembarangan anakanak setelah jajan sampahnya dikumpulkan ke tempat sampah yang terpisah yang keringkering yang basah-basah" (Informan 3b)

Pendapat informan yang ditanyakan pendapat mengenai guru UKS bertanggung jawab menjelaskan manfaat dari UKS untuk warga sekolah rata-rata menawab sudah menjelaskan kepada anak murid dan selalu memberikan pengarahan kepada anak-anak murid.Sedangkan salah satu informan menjawab telah menjelaskan setiap kali mendapatkan pelatihan selalu menjelaskannya juga ke anak murid. Seperti ungkapan berikut ini :

“... eee setiap ada pelatihan eee apa dijelaskan yah ke anak murid" (Informan 3b)

“... baik, memang sesuai dengan bidang yah”(Informan 1a)

Pendapat mengenai bentuk apa saja 
yang harus dimiliki seorang guru UKS ketika ditanyakan kepada informan jawabannya berbeda-beda seperti harus bisa melakukan tensi kepada anak murid, memberikan pertolongan pertama, dan harus mengetahui jelas mengenai trias UKS. Sedangkan salah satu informan mengatakan keahlian yang harus dimiliki guru UKS hanya memberikan sekedarnya tentang ilmu kesehatan yang dia

\section{Umur}

Informasi yang ditanyakan mengenai umur terdiri dari pendapat mengenai kelas berapa saja yang menjadi sasaran utama untuk program UKS dan pendapat mengenai sasaran utama adalah kelas 1,3 dan 6 .

Respon dari semua informan berbedabeda ada yang menjawab semua kelas dari kelas 1-6, ada yang setuju mengenai pendapat sasaran utama adalah kelas 1,3 dan 6 hanya yang membedakan adalah kelas 5 saja. Ada pula yang menjawab sasaran utama hanya kelas 4 alasannya untuk dijadikan dokter cilik (Dokcil). Berikut adalah ungkapannya :

“... nah kalau sasaran untuk dokcil yaitu hanya baru kelas 4 untuk dibina jadi dokcil" (Informan 1b)

"Seluruh sekolah seluruh kelas kelas 1 sampai kelas 6" (Informan 1a)

"Kelas 3,4,5 alasannya ee karna kalo

\section{Sarana Prasarana}

Informasi yang ditanyakan terkait sarana prasarana terdiri dari peralatan apa saja yang menunjang program UKS, peralatan apa saja yang ada di UKS, pendapat mengenai proses penyediaan sarana prasarana untuk kebutuhan UKS, kendala apa saja yang ditemukan selama proses penyediaan sarana prasarana, pendapat mengenai proses pemeliharaan sarana prasarana UKS, pendapat mengenai sarana prasarana apa saja yang dirasa kurang dalam UKS, dan pendapat mengenai UKS sudah berada dikategori standar minimal atau punya. Seperti ungkapa berikut ini :

"Keahlian sebetulnya keahliannya yaa apa yaa itu saja hanya memelihara hanya memberikan sekedarnya apa ilmu yang saya punya gitu aja tentang kesehatan" (Informan 1b)

"Eeem ya harus bisa tentang kesehatan kaya nensi gitu gitu aja sih teh" (Informan 2b)

kelas 1 masih nginduk ke orang tuanya gitu" (Informan 2b)

Pertanyaan diatas juga diperkuat oleh pernyataan dari informan kunci yang mengatakan sasaran utamanya adalah kelas 1,3 dan 5 alasannya adalah untuk kelas 1 karena untuk dilakukan penjaringan kesehatan sedangkan untuk kelas 3 dan 5 alasannya hanya untuk kelas selektif untuk mendapatkan pembinaan mengenai kesehatan gizi dan gigi. Seperti ungkapan berikut :

“... sasaran saya itu sebetulnya semua tapi yang menjadi fokus dari uks itu hanya siswa kelas 1 kalau obesitas itukan kita kerjasama sama petugas gizi kelas 3 sampai kelas 5 terus dengan petugas gigi juga pemeriksaan kelas selektif yah kalau gigi itu kelas 1,3 dan 5 itu dinamakan pemeriksaan berkala”(Informan Kunci b)

standar lengkap atau paripurna.

Semua informan hampir menjawab peralatan yang menunjang berjalannya UKS adalah peralatan fisik seperti tempat tidur, kotak P3K, pengukur tinggi badan dan penimbang berat badan.Ada pula yang menjawab selain peralatan fisik salah satu informan menjawab dari guru-guru lain yang harus mendukung berjalannya UKS.Salah satu informan juga mengungkapkan bahwa sekolah yang dia pimpin telah menggunakan sistem untuk menyimpan data-data murid 
seperti data berat badan dan tinggi badan. Seperti ungkapann berikut ini :

"Yaa... seperti timbangan tinggi badan tempat tidur untuk ini obat-obatan pokonya p3k"(Informan 2b)

“... ck peralatannya yaitu menunjang yang mungkin yaa dari segi guru-gurunya yang menunjang juga terlaksananya ini dari setiap per kelas itu disarankan terus yaa alatalatnya juga seumpanya kotak p3k" (Informan 3b)

“... ya semuanya lah tinggi badan berat badan senter tensi eee kemudian apah buku isihara yah buta warna kemudian ee stelen chart garpu tala reflek hammer semuanya seharusnya ada yah"(Informan Kunci a)

Untuk pertanyaan bagaimana proses penyediaan alat sarana prasarana masingmasing informan menjawab berbeda-beda. Ada salah satu informan yang mendapatkan bantuan dari kerajaan Thailand. Selain itu semua informan menjawab proses penyediaan sarana prasarana adalah menggunakan anggaran sekolah. Seperti ungkapan berikut ini :

“... ee sebagian kita dari kemarin tuh dari bantuan Thailand yah sebagian dari bos dan ini bangunan dari Thailand itu dari kerajaanya dari putri mahacakri putri ke empat atau ketiga gitu dari raja thailand sudah dua kali yah kita dapat bantuan yah mudah mudahan nanti yang ketiga kantin sehat yah hehehe"(Informan 1a)

"Eee yaa kita si terima kemaren tuh paket dari dinas kaya kotak p3k, timbangan, eee patung yang organ tubuh gitu tapi belum sempet diletakkan masih ada diatas lemari"

\section{(Informan 2b)}

"Persediannya yaa ee dari anggaran sekolah kadang-kadang ada juga dari dinas kesehatan yah" (informan 3a)

Hampir semua informan ketika menjawab pertanyaan kendala apa saja yang ditemukan semua hampir menjawab adalah biaya atau dana. Namun ada salh satu informan yang menungkapkan bahwa tidak ada kendala yang menyebabkan proses penyediaan sarana prasaranya menjadi terhambat. Berikut ungkapannya :

"Yaaa.. dananya hehehe dananya pak eman yah, ya dana karna bos itu terbatas yah tidak hanya itu” (Informan 1a)

"Dana yah semuanya juga di inikan oleh dana yah heheh" (Informan 1b)

“... itu si teh kaya biaya gitu susah mau minta biaya dari dinas” (Informan 2b)

Semua informan ketika ditanya bagaimana proses pemeliharaan sarana prasarana di UKS semua hampir menjawab hanyak diletakan atau disimpan diruang UKS atau disimpan didalam lemari. Seperti ungkapan berikut :

“... ya bagaimana ya meliharanya ya inikan ada habis pakai yah bagaimana ya saya juga bingung ini hehe merawat semaksimal mungkin ajalah" (Informan 1b)

"Yaa.. disimpan ditempatnya ya seumpamanya disininya adda ruang uksnya disimpan diruang uks kalau ada yang perlu baru diambil" (Informan 3a)

“... ya kita rawatlah sering kita di apa di apatah kaka kalo erni teh kemaren diperiksa apa ka kalo tensi apa namanya dikalibrasi itu aja"(Informan Kunci a)

Sedangkan untuk pertanyaan mengenai sarana prasarana apa saja yang dirasa kurang dalam UKS hampir semua informan menjawab tensi, peralatan edukasi gigi dan ada juga informan yang menginginkan pendeteksi kuman. Selain itu juga dua informan lainnya mengatakan bahwa ruang untuk uks masih dirasa kurang karena masih bersatu dengan ruang guru atau ruang yang lain. Seperti ungkapan berikut :

“... eee... kalau untuk kita sih ruanga yah soalnya kan ruangan uks kita Cuma segitu bersatu sama ee ruang kepala sekolah kalau ada yang sakit harus harus ngelewatin 
kepala sekolah dulu eeem jadi anak-anak yang sakit lebih sering dibawa keruang guru dari pada ke uks karna ya itu susah jalannya teh" (Informan 2b)

\section{Dukungan}

Informasi yang ditanyakan mengenai dukungan terdiri dari siapa saja yang terlibat dalam program UKS, siapa saja yang menjadi sasaran dari program UKS, siapa yang memberikan pembinaan terhadap penanggung jawab UKS, siapa yang bertanggung jawab memelihara peralatan yang ada di UKS, siapa saja yang pernah melakukan penyuluhan terkai UKS, dan apa saja bentuk kerja sama yang terjalin terkait program UKS.

Hampir semua informan mengatakan mengenai siapa saja yang terlibat dalam program UKS adalah guru, petugas kesehatan dan wali murid atau orang tua murid. Ungkapan dibawah juga didukung oleh ungkapan informan kunci yang mengatakan bahwa yang sangat berperan adalah jajaran petugas kesehatan . Seperti ungkapan berikut ini :

"Yang terlibat eee sudah jelas jejeran pemerintah dinas yah lalu puskesmas sekolah dan warga sekolahnya itu sendiri gitu" (Informan 1a)

“... yaaa kepala sekolah, komite dari puskesmas guru-guru yang lain itu sama warga sekolah aja" (Informan 1b)

Pertanyaan mengenai siapa saja yang memberikan pembinaan terhadap penanggung jawab UKS hampir semua informan mengatakan bahwa yang memberikn pembinaan adalah petugas kesehatan, kepala sekolah dan guru penggung jawab UKS.Sedangkan ada juga yang mengatakan tidak tahu dan hanya mengurusnya sendiri. Seperti ungkapan berikut ini :

\footnotetext{
"Ya jelas penanggung jawab UKS"
}

"Terutama untuk eee kita masih belum ada untuk tensi, kemudian eee untuk sikat gigi model giginya juga kurang yah belum banyak baru ada 1 gitu” (Informan 1a)

\section{(Informan 1a)}

“... saya sendiri kan cuma saya penanggung jawab uks guru-guru lain hanya ya gitu lah heheh" (Informan 1b)

Ungkapan ini juga diperkuat oleh ungkapan dari informan kunci mengatakan bahwa di wilayah kerjanya telah memiliki tim Pembina UKS yang terdiri dari dokter sampai petugas gizi ikut menjadi tim pembina UKS. Seperti ungkapan berikut :

"Pembinaan ya dikita kan mempunyai tim Pembina uks yah mulai dari kepala puskesmas, dokter umum, eee apa namanya tim kaya petugas gizi itu merupakan tim uks jadi itu yang berlima itu biasanya mereka yang ikut membina kalau ada pelatihan "(Informan Kunci b)

Pertanyaan mengenai siapa saja yang pernah melakukan penyuluhan mengenai kesehatan disekolah hampir semua informan menjawab lebih sering adalah petugas kesehatan walau ada dari kepemerintahan lain seperti kelurahan dan komite-komite terkait. Seperti ungkapan berikut :

“...ee... umunya petugas uks dari puskesmas kedung badak itu rutin setiap hari sabtu yah membina dokcil yah dan umumnya juga dari dinkes kota dan pernah juga dari kelurahan tapi dari kelurahan tidak secara mendetail gitu yah"(Informan 1a)

"Yang memberikan penyuluhan yaa dinas kesehatan yah dan puskesmas yah udah itu aja "(Informan 1b)

Informan ketika ditanya mengenai kerja sama apa saja yang telah dilakukan antara sekolah dengan pihak lain jawaban dari masing-masing informan menjawab berbedabeda ada yang menjawab dari perusahaan 
susu, dari puskesmas dan dari intansi pemerintahan thailand. Seperti ungkapan dibawah ini :

“...yaaa.. dancow waktu itu ada pelatihan yah di mana gitu lupa itu tentang dokcil penimbangan berat badan nah itu

\section{PEMBAHASAN}

\section{Pengetahuan}

Hasil wawancara mendalam dengan informan menunjukkan bahwa pengetahuan informan di wilayah UKS CT menunjukan hasil pengetahuan yang lebih baik dari pada UKS CR hal ini diperkuat dengan hasil obsrvasi yang sudah dilakukan.

Hasil ini sejalan dengan penelitian Menurut Lubis (2016) mengatakan bahwa faktor pengetahuan dapat mempengaruhi pelakasanaan uks.Pernyataan ini didukung pula oleh penelitian Rahmawati (2015) menyatakan bahwa pengetahuan dapat mempengaruhi manajemen pengelolaan UKS di sekolah dasar.

Tinjauan analisis diatas menunjukn bahwa pengetahuan informan antara wilayah UKS CR kurang dari pada wilayah UKS CT terutama pada pengetahuan TRIAS UKS. Ini menjadi masukan untuk instansi kesehatan agar dapat menjelaskan secara intensif apa yang dimaksud dengan TRIAS UKS dan kegiatan apa saja yang ada didalamnya karena TRIAS UKS adalah 3 poin utama dalam UKS dan harus dijalankan setiap programnya disekolah-sekolah yang telah memiliki UKS

\section{Sikap}

Berdasarkan hasil wawancara mendalam dengan informan tentang sikap dapat diliihat dengan jawaban yang diberikan dari pertanyaan mengenai pendapat tentang kualitas uks yang ada dimasing-masing sekolah bagi sekolah dengan cakupan yang sudah baik menjawab bahwa UKS yang ada disekolah mereka sudah baik dari kualitasnya tentang apasih namanya iti buku kesehatan anak sekolah itu tatacara mengisinya" (Informan 1b)

"Oh kamikan kalo ada bias apa segala macem itukan dari puskesmas lebih seringnya dari puskesmas" (Informan 2b)

karena memiliki sarana prasarana yang lengkap.Lain halnya dengan sekolah yang memiliki UKS CR mejawab bahwa kualitas UKS yang ada disekolah sudah bagus tetapi masih banyak kekurangan dari segi sarana prasarana maupun dukungan dari guru.

Hal ini sejalan dengan penelitian Ngaini (2013) dalam penelitiannya yang mengatakan bahwa sikap sudah berkategori baik. Penelitian ini juga didukung oleh Lubis (2016) yang mengatakan bahwa sikap anak sekolah memiliki peranan terhadap pelayanan UKS.

\section{Sarana Prasarana}

Sarana Prasarana yang ada di UKS dengan UKS CT sudah jelas sarana prasananya sudah mumpuni ditambah lagi dengan adanya sistem yang dapat menyimpan semua data kesehatan warga sekolah khususnya anak murid. Jawaban dari informan langsung yang mengatakan bahwa sekolahnya sudah memiliki sarana yang cukup baik hanya tinggal melengkapi beberapa sarana prasarana lagi untuk dapat dikategorikan sebagai UKS golongan paripurna. Lain halnya dengan sekolah yang UKS CR sekolah hanya menerima bantuan dari pemerintah berupa kit alat kesehatan yang didalamnya hanya ada pengukur tinggi badan, pengukur berat badan dan lainnya hanya sebagai pelengkap UKS.

Hal ini sejalan dengan data observasi yang telah didapatkn dari 22 sekolah menunjukan hasil masih banyak sekolah yang memiliki keterbatasan sarana prasarana. Hampir semua sekolah yang diobservasi 
hanya memilki sarana prasarana dasar UKS berkategori lengkap belum mencapai ideal namun ada beberapa sekolah yang UKSnya telah mencapai kategori ideal.

Hal ini sejalan dengan penelitian Nugroho (2012) dalam jurnalnya yang menunjukan bahwa sarana dan prasarana memiliki peranan dalam pelaksanaan program UKS. Faktor sarana dan prasarana pula didukung oleh Lubis (2016) dalam penelitiannya mengatakan bahwa sarana dan prasarana memiliki hubungan terhadap pelaksanaan program UKS.

\section{Umur}

Berdasarkan hasil dari wawancara mendalam yang dilakukan oleh peneliti menunjukkan bahwa sasaran utama dari program UKS adalah semua golongan atau semua umur walaupun ada salah satu informan yang mengatakan bahwa secara khusus program UKS hanya di tujukan kepada kelas 4 karena dengan tujuan untuk dapat dijadikan dokcil. Sedangkan informan lain mengatakan bahwa sasaran utamanya adalah kelas 1,3 dan 5 dengan alasan kelas 1 karena akan dilakukannya penjaringan kesehatan sedangkan untuk kelas 3 dan 5 ditujukan untuk pembinaan dokcil dengan alasan mengapa kelas 3 karena agar dapat dijadikan contoh kepada adik-adik kelsnya, sedangkan ketika ditanya anak kelas 6 tidak diikut sertakan alasannya karena anak kelas 6 sudah harus fokus karena sedikit lagi akan lulus sekolah dasar paling hanya diberikan pengetahuan tentang bahaya merokok daan tentang sistem reproduksi.

\section{Dukungan}

Berdasarkan wawancara dengan informan tentang dukungan dari petugas kesehatan ataupun dukungan dari sekolah ataupun dar dukungan orang tua murid sangatlah penting bagi keberlangsungan program UKS. Dimana dukungan petugas kesehatan berperan sebagai fasilitator yang erat hubungannya dengan sekolah untuk memberikan program-program yang telah ditentukan.Sedangkan untuk dukungan dari sekolah juga sangatlah penting karena sekolah sebagai pihak yang menjalankan program UKS yang sesungguhnya ketika pihak dari petugas kesehatan mengunjungi sekolah diharapkan sekolah menerimanya.Sedangkan dukungan dari orang tua murid juga sangat berperan penting masih banyak orang tua yang menolak anaknya untuk disuntik imunisasi ketika ada program terkait. Dengan kata lain sekolah dan petugas kesehatan harus berusaha meyakinkan orang tua agar semua anaknya dapat diimunisasi demi meningkatkan atau memenuhi cakupan program imunisasi yang telah ditentukan.

Hasil ini juga sejalan dengan penelitian dari Amin (2010) mengatakan bahwa faktor dukungan pelaksanaan UKS meliputi penanaman pengetahuan tentang pola hidup sehat terhadap peserta didik secara rutin serta adanya dukungan dan koordinasi pelaksanaan mekanisme organisasi UKS dan pelaksanaan program kerja UKS baik dari sekolah maupun dari tim Pengawas Pembina UKS.

Penelitian ini juga didukung oleh penelitian dari Penelitian Tjomsland dkk (2009) menyatakan bahwa dalam mengembangkan upaya kesehatan di sekolah yang berkesinambungan harus ditunjang oleh stakeholder yang berkepentingan, diantaranya guru. Para guru yang memiliki motivasi baik, akan cenderung berpartisipasi dalam program pengembangan sekolah jika mereka percaya bahwa program tersebut akan menghasilkan hasil yang baik untuk prestasi anak didiknya. 


\section{KESIMPULAN}

Berdasarkan hasil penelitian faktor yang berhubungan dengan kualitas pelayanan UKS pada tingkat sekolah dasar di wilayah kecamatan Tanah Sareal Kota Bogor tahun 2018 dapat disimpulkan bahwa :

1. Pengetahuan informan yang sekolahnya memiliki cakupan UKS lebih tinggi dikatakan lebih baik dari pada informan yang sekolahnya memiliki cakupan UKS lebih rendah. Pengetahuan informan yang lebih baik karena pengalaman yang sudah lama berada di posisi tersebut kalau dari segi pendidikan semua informan sama rata yaitu sarjana yang membedakan hanya pengalamannya. Selain dari pengalaman yang paling berpengaruh adalah sesering apa melakukan pelatihan mengenai UKS sehingga lebih membuat informan memiliki jangkauan pengetahuan yang lebih luas.

2. Sikap mempengaruhi kualitas UKS. Informan yang telah memiliki pengalaman dibidangnya selalu mencari tahu apa yang harus dilakukan didalam program UKS sedangkan informan dengan cakupan lebih tinggi karena merasa sarana prasarana UKS sudah bagus jadi sudah cukup tanpa diimbangi dengan keahlian yang harus dimiliki seorang guru UKS.

3. Umur. Informan yang menjelaskan mengenai sasaran utama bisa disimpulkan secara garis besar adalah seluruh golongan umur mulai dari anak murid hingga guru-guru dan staff yang terkait. Sedangkan untuk kelas-kelas tertentu hanya dijadikan untuk kelas klasifikasi seperti yang sudah dijelaskan sebelumnya kelas 1 dikhusukan untuk penjaringan kesehatan sdangkan kelas 3 dan 5 di khususkan untuk program dokcil, dan edukasi kesehatan perseoranganpun sudah diberikan oleh petugas kesehatan mengenai kesehatan gizi, kesehatan gigi dan lainnya

4. Sarana Prasarana sangat mempengaruhi kualitas dari suatu UKS dari semua sekolah sebetulnya masih banyak yang belum mempunyai srana prasarana yang lengkap salah satu yang paling banyak belum dimiliki oleh sekolah yang ada diwilayah Kecamatan Tanah Sareal adalah gedung tersendiri khusus UKS yang tidak bersatu dengan ruangan apapun.

5. Dukungan dari pihak petugas kesehatan sudah baik dari segi memberikan penyuluhan sampai memberikan pelayanan kesehatan berupa imunisasi dan lainnya. Sedangkan dari pihak wali murid masih memiliki kendala yang cukup membuat program UKS tidak berjalan yang sesuai dengan yang telah ditentukan. 


\section{DAFTAR PUSTAKA}

[1] Afandi Lutfi (2012) Pelaksanaan Program Usaha Kesehatan Sekolah Di SD Negeri Se-Kecamatan Samigaluh Kabupaten Kulon Progo Tahun 2012. Universitas Negeri Yogyakarta. Diakses pada tahun 2013.

[2] Amin Mahfud (2015) Pelaksanaan Program Usaha Kesehatan Sekolah di Sekolah Dasar Negeri se-Kecamatan Alian Kabupaten Kebumen tahun Ajaran 2015/2016. Universitas Negeri Semarang. Diakses tahun 2015.

[3] Ayodeji M Adebayo et.al (2015) Knowledge of School Health Programme among Public Primary School Teachers in Oyo State, SouthWest Nigeria: A Rural-Urban Comparative Study Vol.19, No.3. Published by Elsevier.Diaksespada September 2015

[4] B Russell (1960) School Health: SCHOOL HEALTH ATTENDANTS. Canadian Journal of Public Health / Revue Canadienne de Santé Publique Vol. 51, No. 11. Diakses pada 11 november 1960.

[5] Buku Pedoman Akselerasi Pembinaan dan Pelaksanaan UKS. Jakarta : 2015

[6] Buku Pedoman Pelaksanaan UKS di Sekolah. Kementrian Pendidikan dan Kebudayaan. Jakarta : 2012

[7] Celia Marieset.al (2005) The FRESH initiative: school health in the context of education for all. JStor.Diaksespada 03 Januari 2005.

[8] Dinkes Kota Bogor (2017) Pencapaian Program Usaha Kesehatan Sekolah di Kota Bogor. Bogor : Dinkes 2017

[9] Fallon Tileyet.al (2014) Healthy Lunchbox Challenge Helps Influence Healthy Eating Habits in Children.Published by
Elsevier.Diaksespada 18 Februari 2014 Philadelphia.

[10] Frederic .D. Wollynsky (1978) Assessing the Effects of Predisposing, Enabling, and Illness-Morbidity Characteristics on Health Service Utilization.Vol.19, No.4.JStor. Diakses pada Desesmber 1978.

[11] Health Care Lessons Learned in the Aftermath (2001). Published by Elseiver.Diaksespada 09 Desember 2014 New York.

[12] Kopelman et.al.(1989) Children and Health Care.Springer, Diakses 1989.

[13] Korin M.R (2016) Health Promotion for Children and Adolescents. Published by Springer.Diakses pada 2016

[14] Laporan Pelaksanaan Kegiatan Usaha Kesehatan Sekolah UPTD Puskesmas Kayumanis.

[15] Laporan Pelaksanaan Kegiatan Usaha Kesehatan Sekolah UPTD Puskesmas Kedung Badak.

[16] Laporan Pelaksanaan Kegiatan Usaha Kesehatan Sekolah UPTD Puskesmas Pondok Rumput.

[17] Laporan Pelaksanaan Kegiatan Usaha Kesehatan Sekolah UPTD Puskesmas Tanah Sareal.

[18] Leschied, Alan W. et.al (2018) Handbook of School-Based Mental Health Promotion An EvidenceInformed Framework for Implementation. Published by Springer diakses pada 2018.

[19] Lubis Nailaufar Widya (2016) Faktorfaktor yang berhubungan dengan pelaksanaan Usaha Kesehatan Sekolah di Tingkat Sekolah Dasar Wilayah Kerja Puskesmas Pamulang Kota Tanggerang Selatan. Universitas Islam Negeri Syarif Hidayatullah. Jakarta : 
2016

[20] Macklem, Gayle L (2011) EvidenceBased School Mental Health Services.Published By

Springer.Diaksespada 2011

[21] Michael W. Beetset.al (2016) Healthy Eating standards still not fully adopted among YMCA after-school programs. Published by Elsevier.DiaksesPada 08 September 2016 Piladelphia

[22] Mortality and Morbidity Weekly Report (2011) School Health Guidelines to Promote Healthy Eating and Physical Activity Vol.60 No.5. Published by JStor. Diakses pada 16 September 2011.

[23] Nugroho Suryo (2015) Pelaksanaan Usaha Kesehatan Sekolah di Sekolah Dasar Negeri 1 Grogol Kecamatan Bambanglipuro Kabupaten Bantul. Universitas Negeri Yogyakarta. Diakses pada tahun 2015.

[24] Peraturan Bersama 4 Menteri (2014). Pembinaan dan Pengembangan Usaha Kesehatan Sekolah. Jakarta 2014.

[25] Profil Kecamatan Tanah Sareal 2017. Kota Bogor.

[26] Rahmawati et.al (2015) Manajemen Usaha Kesehatan Sekolah. Universitas Negri Malang. Diakses pada tahun 2015.
[27] Septiani Agnes (2016) Analisis Kebijakan Usaha Kesehatan Sekolah di Dinas Pendidikan Dasar Kabupaten Bantul. Universitas Negeri Yogyakarta. Diakses pada tahun 2016.

[28] Suryani (2013) Pelaksanaan Pembinaan Kesehatan Lingkungan Sekolah Dasar Wilayah Kerja Puskesmas Bantar Khalipah Kecamatan Percut Sei Tuan Kabupaten Deli Serdang. Diakses pada tahun 2013.

[29] Suryani Yani (2012) Analisis Manajemen Program Usaha Kesehatan Gigi Sekolah di Puskesmas Kodya Jakarta Barat. Universitas Indonesia. Diakses pada tahun 2012.

[30] Sugiyono (2011) Metodologi Penelitian Kuantitatif, Kualitatif dan $R \& D$. Bandung; Alfabeta.

[31] St. Louis, MO, USA (2009) Results of the Third School Nutrition Dietary Assessment Study Published. Elseiver.Daikses 01 Februari 2009.

[32] Untara Andi (2013) Survei Pelaksanaan Program Usaha Kesehatan Sekolah di Sekolah Dasar se-Kecamatan Kretek Kabupaten Bantul. Universitas Negeri Yogyakarta. Diakses pada tahun 2013. 